\title{
Prática como componente curricular em um curso de licenciatura em matemática: uma análise à luz da teoria da atividade
}

Rafael Borini Martins Costa

\section{Borini}

borinirafa@gmail.com

orcid.org/0000-0001-8327-9147

Universidade Federal do Paraná (UFPR),

Curitiba, Paraná, Brasil

\section{Flávia Dias de Souza}

flaviad@utfpr.edu.br

orcid.org/0000-0001-8327-9147

Universidade Tecnológica Federal do

Paraná (UTFPR), Curitiba, Paraná, Brasil

\section{RESUMO}

O artigo decorre de uma pesquisa de mestrado e teve como objetivo investigar possibilidades de organização da prática como componente curricular (APCC) que possam favorecer a articulação entre teoria e prática na formação inicial. O estudo foi realizado em um curso de Licenciatura em Matemática e utilizou como base os pressupostos teóricos da teoria da atividade, dentre os quais destacam-se os conceitos de atividade teórica, atividade prática e práxis. Para o desenvolvimento da pesquisa, adotou-se a pesquisa documental, utilizando-se dos diários de classes e dos planos de ensino detalhados das disciplinas lecionadas no primeiro semestre de 2015 e que apresentavam parte da sua carga horária destinada à prática como componente curricular do curso em estudo. O trabalho fundamentou-se teoricamente em Leontiev $(1983,1988)$ para a discussão de elementos da teoria da atividade e em Sánchez Vázquez $(1980,2011)$ para o aprofundamento dos conceitos de atividade teórica, atividade prática e práxis. O processo de análise deu-se sob dois aspectos: i) a presença das APCCs nos três eixos de formação previstos no curso e; ii) a natureza das atividades de APCCs presentes no curso. Nesse primeiro aspecto a análise centrou-se em compreender as recorrências de atividades entendidas como APCCS nos eixos de formação específica de conteúdo matemático, formação pedagógica geral e formação em educação matemática. No segundo aspecto de análise constituíram-se cinco grupos de atividades, dentre os quais o grupo "Atividades de criação, estratégias didáticas, elaboração, planejamento de atividades ou materiais para a sala de aula" revelou mais indícios de possíveis articulações teoria e prática. Buscou-se, com a pesquisa, discutir as atividades desenvolvidas como APCCs, trazer contribuições aos professores formadores na organização de suas atividades de ensino, elencando características de atividades que revelam indícios de articulação teoria e prática.

PALAVRAS-CHAVE: Prática como componente curricular. Atividade teórica. Atividade prática. Práxis. Licenciatura em matemática. 


\section{INTRODUÇÃO}

Os A Resolução do Conselho Nacional de Educação/Conselho Pleno (CNE/CP) no 01 de 18 de fevereiro de 2002 estabelece que a prática não pode ficar em um espaço isolado ou reduzida ao estágio. Pelo contrário, ela deve estar em todo o curso, desde o primeiro semestre e em todas as disciplinas e áreas.

Posteriormente, no ano de 2015, foram aprovadas as novas "Diretrizes para os cursos de Licenciatura no Brasil", nas quais consta no artigo 13, parágrafo 3 , a seguinte afirmação: "Deverá ser garantida, ao longo do processo, efetiva e concomitante relação entre teoria e prática, ambas fornecendo elementos básicos para o desenvolvimento dos conhecimentos e habilidades necessários à docência." (BRASIL, 2015, p. 11).

As referidas diretrizes intencionam relacionar a teoria e a prática na formação de professores no país de forma articulada, de modo que nenhuma se sobreponha a outra, superando duas noções bastante presentes no discurso educacional: uma de que a teoria é mais importante do que a prática, e outra de um acentuado "praticismo", no qual a prática é mais importante na profissão docente.

Diante desse cenário, o presente trabalho decorre de pesquisa de mestrado realizada no Programa de Pós-graduação em Educação em Ciências e em Matemática (PPGECM), da Universidade Federal do Paraná (UFPR) e buscou investigar a seguinte problemática: "Que possibilidades de organização da prática como componente curricular em um curso de Licenciatura em Matemática podem favorecer a articulação entre teoria e prática na formação inicial de professores de matemática?". Teve como objetivo investigar possibilidades de organização da prática como componente curricular (APCC) em um curso de Licenciatura em Matemática que possam favorecer a articulação entre teoria e prática na formação inicial, considerando-se pressupostos teóricos da teoria da atividade, dentre os quais destacam-se os conceitos de atividade teórica, atividade prática e práxis.

Como referencial teórico, o trabalho partiu de estudos acerca da legislação vigente para os cursos de licenciatura no Brasil, de pressupostos teóricos da teoria da atividade propostos por Leontiev $(1983,1988)$ e do conceito de práxis em Sánchez Vázquez $(1980,2011)$.

\section{SOBRE A PRÁTICA COMO COMPONENTE CURRICULAR}

A prática como componente curricular (APCC) foi denominada pela primeira vez no Parecer CNE/CP de 28/2001, conforme segue:

A prática como componente curricular é, pois, uma prática que produz algo no âmbito do ensino. Sendo a prática um trabalho consciente cujas diretrizes se nutrem do Parecer 9/2001 ela terá que ser uma atividade tão flexível quanto outros pontos de apoio do processo formativo, a fim de dar conta dos múltiplos modos de ser da atividade acadêmico-científica. Assim, ela deve ser planejada quando da elaboração do projeto pedagógico e seu acontecer deve se dar desde o início da duração do processo formativo e se estender ao longo de todo o seu processo. Em articulação intrínseca com o estágio supervisionado e com as atividades de trabalho acadêmico, ela concorre conjuntamente para a formação da identidade do professor como educador. (BRASIL, 2001c, p. 9). 
Com o surgimento da prática como componente curricular na legislação, o ano de 2002 também marca a aprovação das Resoluções CNE/CP nำ, de 18 de fevereiro de 2002, intitulada "Diretrizes Curriculares Nacionais para a Formação de Professores da Educação Básica, em nível superior, curso de licenciatura, de graduação plena", sendo assim como o próprio título já diz, as diretrizes para todos os cursos de licenciatura no Brasil.

Ainda da análise da Resolução CNE/CP 1/2002, acerca da dimensão prática, advém:

Art. 13 - Em tempo e espaço curricular específico, a coordenação da dimensão prática transcenderá o estágio e terá como finalidade promover a articulação das diferentes práticas, numa perspectiva interdisciplinar.

$\S 1$ ㅇ A prática será desenvolvida com ênfase nos procedimentos de observação e reflexão, visando à atuação em situações contextualizadas, com o registro dessas observações realizadas e a resolução de situações problema.

§ 2ㅇ A presença da prática profissional na formação do professor, que não prescinde da observação e ação direta, poderá ser enriquecida com tecnologias da informação, incluídos o computador e o vídeo, narrativas orais e escritas de professores, produções de alunos, situações simuladoras e estudo de casos. (BRASIL, 2002a, p. 6).

Desse documento tem-se a definição de 400 horas para a prática como componente curricular, durante toda a licenciatura, e desde seu início; enquanto ao estágio supervisionado ficam destinadas também 400 horas, mas com seu início a partir da segunda metade do curso, sendo que a duração mínima de um curso de licenciatura deverá ser de três anos letivos (seis semestres letivos).

As resoluções CNE/CP 01 e 02/2002 permaneceram como diretrizes dos cursos de licenciatura por treze anos, até que no ano de 2015 foram aprovadas novas diretrizes para os cursos de licenciatura no Brasil. Com sua aprovação no dia 1ำ de julho de 2015, é regulamentada a Resolução CNE/CP no 2, que "Define as Diretrizes Curriculares Nacionais para a formação inicial em nível superior (cursos de licenciatura, cursos de formação pedagógica para graduados e cursos de segunda licenciatura) e para a formação continuada." (BRASIL, 2015, p. 1).

Com o intuito de entender os principais elementos previstos na nova legislação, apresentamos as mudanças centrais e os pontos de encontro entre as Resoluções CNE/CP 1 e 2 de 18 e 19 de fevereiro de 2002, respectivamente, e as novas diretrizes para os cursos de licenciatura no Brasil. $O$ quadro a seguir apresenta algumas das alterações que ocorreram nas novas diretrizes em comparação com a Resolução 01/2002. 
Quadro 1 - Comparação das Resoluções CNE/CP de 2002 e 2015

\begin{tabular}{|c|c|}
\hline $\begin{array}{c}\text { Resoluções CNE/CP } 1 \text { de } 18 \text { de } \\
\text { Fevereiro de } 2002\end{array}$ & $\begin{array}{c}\text { Resolução CNE/CP } n^{\circ} 2 \text {, de } 1^{\circ} \text { de } \\
\text { Julho de } 2015\end{array}$ \\
\hline $\begin{array}{l}\text { Art. } 6^{\circ} \text { Na construção do projeto pedagógico } \\
\text { dos cursos de formação dos docentes, serão } \\
\text { consideradas: } \\
\text { I - as competências referentes ao } \\
\text { comprometimento com os valores } \\
\text { inspiradores da sociedade democrática; } \\
\text { II - as competências referentes à } \\
\text { compreensão do papel social da escola; } \\
\text { III - as competências referentes ao domínio } \\
\text { dos conteúdos a serem socializados, aos } \\
\text { seus significados em diferentes contextos e } \\
\text { sua articulação interdisciplinar; } \\
\text { IV - as competências referentes ao domínio } \\
\text { do conhecimento pedagógico; } \\
V \text { - as competências referentes ao } \\
\text { conhecimento de processos de investigação } \\
\text { que possibilitem o aperfeiçoamento da prática } \\
\text { pedagógica; } \\
\text { VI - as competências referentes ao } \\
\text { gerenciamento do próprio desenvolvimento } \\
\text { profissional. } \\
\S \text { 10 O conjunto das competências } \\
\text { enumeradas neste artigo não esgota tudo que } \\
\text { uma escola de formação possa oferecer aos } \\
\text { seus alunos, mas pontua demandas } \\
\text { importantes oriundas da análise da atuação } \\
\text { profissional e assenta-se na legislação } \\
\text { vigente e nas diretrizes curriculares nacionais } \\
\text { para a educação básica. } \\
\S 3^{\circ} \text { A definição dos conhecimentos exigidos } \\
\text { para a constituição de competências deverá, } \\
\text { além da formação especifica relacionada às } \\
\text { diferentes etapas da educação básica, } \\
\text { propiciar a inserção no debate } \\
\text { contemporâneo mais amplo, envolvendo } \\
\text { questões culturais, sociais, econômicas e o } \\
\text { conhecimento sobre o desenvolvimento } \\
\text { humano a própria docência, }\end{array}$ & 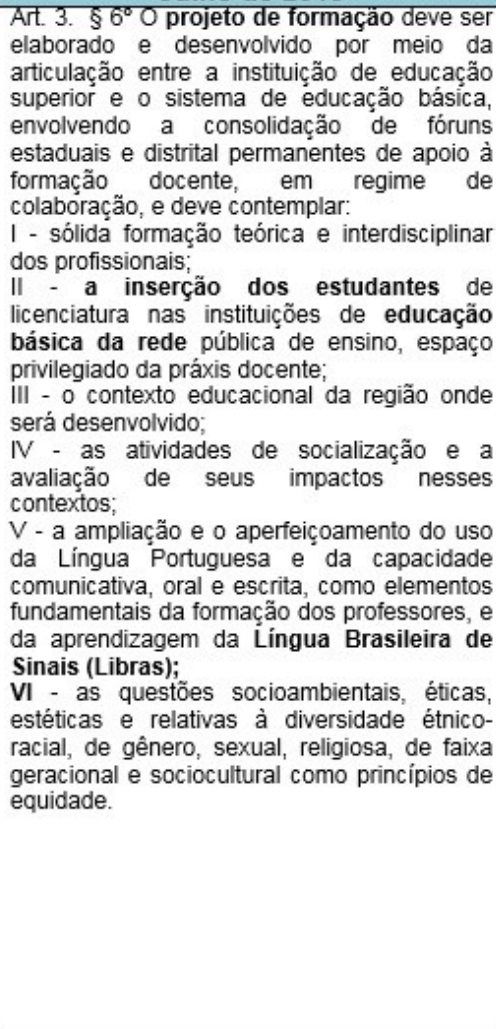 \\
\hline
\end{tabular}

Fonte: Autoria própria (2017).

Referente às mudanças na carga horária para os cursos de licenciatura, a nova legislação prevê alteração de carga horária total mínima de 2800 horas para 3200 horas, com integralização em, no mínimo, quatro anos.

Sobre a prática como componente curricular (APCC), objeto em estudo, a carga horária de 400 horas já prevista na Resolução de 2002, é mantida nas diretrizes de 2015, com uma pequena alteração no texto que passa de "vivenciada ao longo do curso" para "distribuídas ao longo do processo formativo". Em todo o texto das diretrizes não há referências explícitas sobre do que se trata a APCC, apenas indicação de sua permanência e de carga horária prevista. Assim, embora a Resolução 01/2002 tenha sido revogada, as orientações do Art. 12 dessa Resolução permanecem constituindo-se referência para a organização das atividades de prática como componente curricular. Cabe ressaltar do parecer que antecede a Resolução de 2002 que:

Todas as disciplinas que constituem o currículo de formação e não apenas as disciplinas pedagógicas têm sua dimensão prática. É essa dimensão prática que deve estar sendo permanentemente trabalhada tanto na perspectiva da sua aplicação no mundo social e natural quanto na perspectiva da sua didática. (BRASIL, 2001, p. 5).

Diante da necessidade de investigar quais possibilidades de organização da prática como componente curricular em um curso de Licenciatura em Matemática podem favorecer a articulação entre teoria e prática na formação inicial de professores de matemática, colocamo-nos no movimento de que é preciso ampliar 
as compreensões acerca do conceito de prática. Esse estudo, à luz do referencial teórico adotado, nos conduz ao estudo dos conceitos de atividade teórica, atividade prática e, por consequência, o conceito de práxis.

\section{ATIVIDADE TEÓRICA E ATIVIDADE PRÁTICA NA CONSTITUIÇÃO DA PRÁXIS}

Partindo do conceito de atividade em Leontiev, entende-se que em uma atividade, o objeto, este em mudança e desenvolvimento, relaciona-se a um motivo, o qual por sua vez a impulsiona. "A ação individual (ou grupal) é impulsionada por uma meta consciente. Embora as ações sejam provocadas pelo motivo da atividade, elas parecem ser dirigidas a uma meta, enquanto a mesma ação pode servir a diferentes atividades." (LEONTIEV, 1978 apud DANIELS, 2003, p. 116).

Retornamos ao professor que se encontra na necessidade de elaborar um plano envolvendo a prática como componente curricular (conhecimentos docentes para futuro professor) para seus alunos. Na sua elaboração, o professor procura um objeto para fazer com que seus alunos entrem em atividade de estudo ou de aplicação de conhecimentos próprios da docência. A ação do indivíduo ou do grupo será guiada à uma meta consciente (condição oferecida pelo professor em seu planejamento) e a mesma ação pode servir para diferentes atividades, de diferentes sujeitos. Com isso, Leontiev vai mais além e elabora o que considera ser a estrutura hierárquica da atividade.

Figura 1 - Estrutura hierárquica da atividade

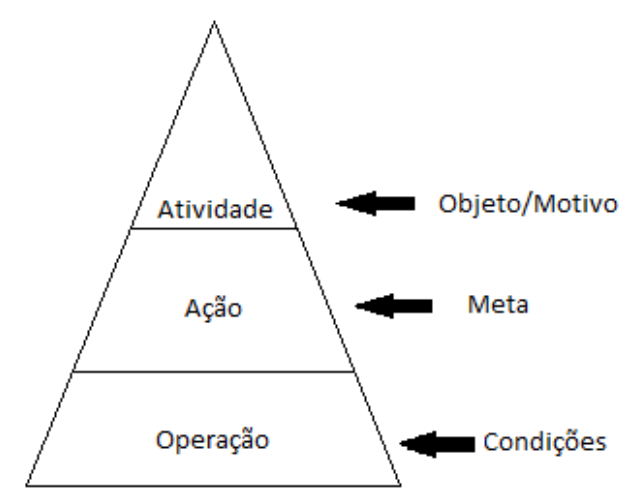

Fonte: DANIELS (2003, p.117).

Tomando esses elementos e relacionando-os com nosso tema de pesquisa, o professor, enfrentando a necessidade de elaborar uma atividade que incorpore a prática como componente curricular, como mencionamos anteriormente, pode definir o conjunto de ações que serão tomadas para que os alunos encontrem os elementos da prática na disciplina ou no caráter escolar. Esse conjunto de ações podem envolver situações simuladas em uma sala de aula, ou até mesmo a visita em escolas ou centros de ensino, mas se o aluno realizar as ações apenas com o intuito de obter a nota mínima para progredir no curso esse será um motivo compreensível; enquanto o aluno que realizar as atividades solicitadas buscando os elementos da docência e da prática para sua formação como futuro professor, gozará então de um motivo eficaz. 
Por fim, nesse processo de compreensão da pirâmide hierárquica da teoria da atividade elaborada por Leontiev, adentramos nas operações que estão intimamente ligadas ao processo de ação, que por sua vez se relacionam com a atividade. A operação é o resultado da transformação de uma ação e é originada como resultado da sua inserção dentro de outras ações até que realize a "tecnificação" da ação. Como Leontiev define: “(...) a gênese da ação está em sua relação de intercâmbio com a atividade, toda operação é o resultado de uma transformação de ação, originada como resultado de sua inserção dentro de outra ação e o início da 'tecnificação' da mesma." (LEONTIEV, 1983, p. 88, tradução nossa).

Referente à necessidade, ela poderá ser a desencadeadora de todas as operações, ações e atividades, mas também poderá ser gerada por atividades e ações realizadas pelos sujeitos na atividade humana. Mas e o professor da universidade que tem como interesse a formação do futuro professor da educação básica? Ao nos referirmos à atividade do professor universitário na formação inicial dos futuros professores, é preciso compreender de que atividade estamos tratando, o que nos leva à necessidade de discutir os conceitos de atividade prática e teórica.

Partimos inicialmente da compreensão de que a atividade prática é aquela "que se manifesta no trabalho humano, na criação artística (...) é uma atividade adequada a fins, cujo cumprimento exige (...) certa atividade cognitiva." (SÁNCHEZ VÁZQUEZ, 2011, p. 227). Em seu trabalho, Sánchez Vázquez (2011) também relaciona a atividade prática como sendo uma atividade real, objetiva ou material. Na mesma direção, Ribeiro (2011) também menciona:

\footnotetext{
Por atividade prática entende-se a "atividade objetiva" cujo objeto é a natureza, a sociedade ou os homens reais e cujo fim é a transformação da realidade, do mundo natural ou social na direção da satisfação de determinada necessidade humana, na qual o resultado é a materialização de uma nova realidade. (RIBEIRO, 2011, p. 57).
}

Quando mencionamos o conceito de atividade, nos referimos às transformações que o indivíduo realiza para satisfazer suas necessidade, tanto subjetivamente como objetivamente. Mas para a atividade prática, essas transformações e as ações realizadas se caracterizam apenas no mundo real, da matéria prima visível. A atividade prática existe pelo homem e para o homem.

Enquanto a atividade prática pode ser compreendida como atividade objetiva, como situamos anteriormente, podemos entender a atividade teórica como uma "atividade subjetiva", que não tem como objeto a natureza, a sociedade, como a atividade prática.

Segundo Sánchez Vázquez, na atividade teórica: psíquicos que só tem existência subjetiva - ou os conceitos, teorias, representações ou hipóteses que têm uma existência ideal. O fim imediato da atividade teórica é elaborar ou transformar idealmente - e não realmente essa matéria-prima, para obter, como produtos, teorias que expliquem uma realidade presente, ou modelos que prefigurem idealmente uma realidade futura. A atividade teórica proporciona um conhecimento indispensável para transformar a realidade, ou traça fins que antecipem idealmente sua 
transformação, mas tanto em um como no outro caso a realidade efetiva permanece intacta. (SÁNCHEZ VÁZQUEZ, 2011, p. 234).

Então enquanto a atividade prática está agindo na natureza, a teórica está agindo sobre o sujeito, mas não transformando a matéria-prima física, e sim mudando ideias, teorias e percepções no indivíduo ou num grupo. Isso então torna a atividade teórica aquilo que transforma o ideal (o mundo das ideias, da consciência); contudo, isso não faz dela menos importante do que a atividade prática que transforma o real.

Nesse sentido, como mencionado por Sánchez Vázquez, a atividade teórica proporciona um conhecimento indispensável para transformar a realidade, aquela que é modificada pela atividade prática, o que nos indica a íntima relação entre a atividade prática e a teórica.

As ações humanas buscam satisfazer necessidades do homem. Como apresentamos anteriormente, essas ações tendem a transformar um objeto material, ou essas ações podem acontecer no âmbito teórico ou da consciência.

Essas ações objetivas, que transformam o objeto (atividade prática) e as ações realizadas na consciência (atividade teórica), podem se constituir como um movimento de práxis. Para isso, partimos do entendimento de que "Toda práxis é atividade, mas nem toda atividade é práxis." (SÁNCHEZ VÁZQUEZ, 2011, p. 221). Pois se consideramos que estamos realizando apenas a atividade prática, desconexa com a atividade teórica, embora estejamos realizando uma atividade, ela não se configurará como sendo práxis. De acordo com Sánchez Vázquez:

\footnotetext{
Em suma, a práxis se apresenta como uma atividade material, transformadora e adequada a fins. Fora dela, fica a atividade teórica que não se materializa, na medida em que é atividade espiritual pura. Mas, entretanto, não há práxis como atividade puramente material, isto é, sem a produção de fins e conhecimentos que caracteriza a atividade teórica. (SÁNCHEZ VÁZQUEZ, 2011, p. 239).
}

Não cabe supervalorizar uma em detrimento da outra, pois é necessário relacionar as duas para que se constitua uma mudança real e ideal na matériaprima. Como destacam as autoras Souza e Moretti:

\footnotetext{
Assim, se por um lado a prática é o fundamento da teoria, por outro a teoria não tem como função justificar a prática e sim servir-lhe de guia e possibilidade de esclarecimento, muitas vezes estabelecendo relativa autonomia em relação à primeira e até se antecipando a ela. (SOUZA e MORETTI, 2015, p. 34).
}

Assim, faz-se mister tomar cuidado para não nos atermos no "practicismo" do senso comum que se dobra ao pensamento de uma prática esvaziada de elementos teóricos e centrada no "fazer pelo fazer", ou ainda a prática sem ou com pouca teoria justificada pelo entendimento de que o verdadeiro conhecimento se reduz ao útil.

Cabe compreender a dependência mútua da teoria e da prática, em que a prática é o fundamento da teoria e que para ela irá voltar dialeticamente. Cabe, ainda, compreender que a práxis como sendo a relação da atividade teórica-prática implica diretamente na organização das atividades de prática como componente curricular, pois elas não poderão ser esvaziadas de nenhuma das duas, não 
recorrendo a uma visão do senso comum de uma prática sem teoria ou apenas com o mínimo dela. Ou seja, em nosso entendimento a prática como componente curricular só pode ser entendida nessa relação entre a atividade teórica e atividade prática, na direção da práxis.

Assim a elaboração de atividades em que a "A unidade da teoria e da prática, pressupõe, portanto, sua mútua dependência" (SÁNCHEZ VÁZQUEZ, 2011, p. 264) favorece a formação dos futuros professores e, em particular, a dos professores de matemática.

\section{DA METODOLOGIA AO PROCESSO DE ANÁLISE}

Com o intuito de investigarmos a problemática de pesquisa à luz do conceito de prática, circunstanciado em princípios da teoria da atividade, adotamos a pesquisa documental como modo de apropriação do objeto de pesquisa. A análise deu-se utilizando os diários de classes e os planos de ensino detalhados das disciplinas lecionadas no primeiro semestre de 2015 e que apresentavam parte da sua carga horária destinada a prática como componente curricular. O curso cujas APCCs foram objeto de análise foi o de Licenciatura em Matemática, da Universidade Tecnológica Federal do Paraná, campus Curitiba.

Para realizar a investigação, recorremos ao projeto de abertura do curso, datado de 2010, disponível no site da UTFPR, pois, até o momento das análises, o curso ainda não possuía projeto pedagógico completo, encontrando-se esse em processo de construção pelo Núcleo Docente Estruturante do Curso. Como ponto de partida para a organização e análise dos dados optamos pela formulação de perguntas guia, dentre as quais destacam-se: o que o projeto menciona sobre prática como componente curricular?; o que o projeto menciona sobre "prática" no curso?; como está distribuída a APCC no curso?; como as disciplinas com APCC estão distribuídas nos semestres?. A proposição dessas perguntas norteou todo o processo de captação dos dados no decorrer da investigação.

A tabela a seguir apresenta o número total de disciplinas de cada eixo formativo: quantas delas apresentam horas destinadas a APCC; a porcentagem de disciplinas com APCC em cada eixo; e o total de horas disponibilizadas para cada eixo de formação.

Tabela 1 - Relação disciplinas e APCCs no curso

\begin{tabular}{|c|c|c|c|c|}
\hline Eixo de Formação & $\begin{array}{c}\mathrm{N}^{\circ} \\
\text { disciplinas }\end{array}$ & $\begin{array}{c}\mathrm{N}^{\circ} \\
\text { Disciplinas } \\
\text { com APCC }\end{array}$ & $\begin{array}{c}\text { \% das disciplinas } \\
\text { com APCC por eixo } \\
\text { de formação }\end{array}$ & $\begin{array}{c}\text { Horas aula } \\
\text { de APCC }\end{array}$ \\
\hline $\begin{array}{l}\text { Específicas de conteúdo } \\
\text { matemático (ESP) }\end{array}$ & 23 & 17 & $73,91 \%$ & 326 \\
\hline Pedagógicas Gerais (PG) & 17 & 3 & $17,64 \%$ & 35 \\
\hline Educação Matemática (EM) & 7 & 7 & $100 \%$ & 119 \\
\hline Total* & 46 & 27 & $58,69 \%$ & $480^{*}$ \\
\hline
\end{tabular}

*Sem realizar a conversão para as aulas de 50 minutos.

Fonte: Projeto de Abertura do Curso (2010). 
Da análise dos diários de classe do primeiro semestre de 2015, as APCCs foram classificadas em 36 itens de maior abrangência. Com essas informações, foi elaborado o quadro a seguir, composto da junção de diversas atividades descritas como sendo de APCC, para que fosse possível organizar os dados da pesquisa.

Quadro 2 - Descrição de APCCs nos diários de classe

\begin{tabular}{|c|c|}
\hline & \\
\hline $\begin{array}{l}01 \text { - Leitura de artigo ou texto envolvendo tema da } \\
\text { disciplina } \\
02 \text { - Resolução de exercícios propostos. } \\
03 \text { - Apresentação/Seminário para a turma de um } \\
\text { tema proposto. } \\
04 \text { - Pesquisa de artigo/Material para disciplina. } \\
05 \text { - Criação de Material concreto. } \\
06 \text { - Elaboração de atividade. } \\
07 \text { - Planejamento de uma aula. } \\
08 \text { - Participação em evento da instituição. } \\
09 \text { - Elaboração de uma questão sobre o tema } \\
\text { proposto. } \\
10 \text { - Lista de exercícios. } \\
11 \text { - Estudo de softwares no ensino de Matemática. } \\
12 \text { - Estudo de Legislação/Diretrizes. } \\
13 \text { - Discussão sobre tema proposto. } \\
14 \text { - Uso de softwares no ensino de Matemática. } \\
15 \text { - Análises de Projetos Políticos Pedagógicos } \\
\text { (PPP). } \\
18 \text { - Análise de jogos para o ensino de Matemática. } \\
19 \text { - Elaboração de projeto de pesquisa. } \\
\text { audivos. }\end{array}$ & $\begin{array}{l}20 \text { - Aplicação de conteúdo proposto pela disciplina. } \\
21 \text { - Apresentação para a turma de exercício } \\
\text { resolvido pelo aluno. } \\
22 \text { - Elaboração de um mapa conceitual. } \\
23 \text { - Orientações para elaboração de relatórios. } \\
24 \text { - Organização curricular e planejamento didático. } \\
25 \text { - Entrega de relatório. } \\
26 \text { - Aplicação do conteúdo proposto na Educação } \\
\text { Básica. } \\
27 \text { - Estudo de casos no ensino com Modelagem } \\
\text { Matemática. } \\
28 \text { - Estratégias didáticas que possibilitam o uso de } \\
\text { Modelagem Matemática em sala de aula. } \\
29 \text { - Orientações para desenvolvimento de projetos } \\
\text { com Modelagem Matemática. } \\
30 \text { - Discussão de Educação Ambiental e Modelagem } \\
\text { Matemática. } \\
31 \text { - Uso de Vídeo. } \\
32 \text { - Indicação do conteúdo matemático trabalhado na } \\
\text { aula. } \\
33 \text { - Estudo dos textos de Paulo Freire. } \\
34 \text { - Análise de conteúdo no livro didático. } \\
35 \text { - Análise do livro didático. } \\
36 \text { - Descrição de APcC indefinida. }\end{array}$ \\
\hline
\end{tabular}

Fonte: Autoria própria (2017).

De posse dos dados documentais organizados, o movimento de análise das APCCs foi conduzido sob dois aspectos: i) a presença das APCCs nos três eixos de formação previstos no curso e; ii) a natureza ou "tipo das atividades" de APCCs presentes no curso.

Da análise das disciplinas com APCCs nos eixos de formação: disciplinas específicas de conteúdo matemático, disciplinas de formação pedagógica geral e disciplinas de educação matemática e das descrições constantes dos diários de classe, foi elaborado um diagrama em que figuram os tipos de atividades e sua presença nos diferentes eixos:

Figura 2 - Intersecção APCCs nos eixos de formação 


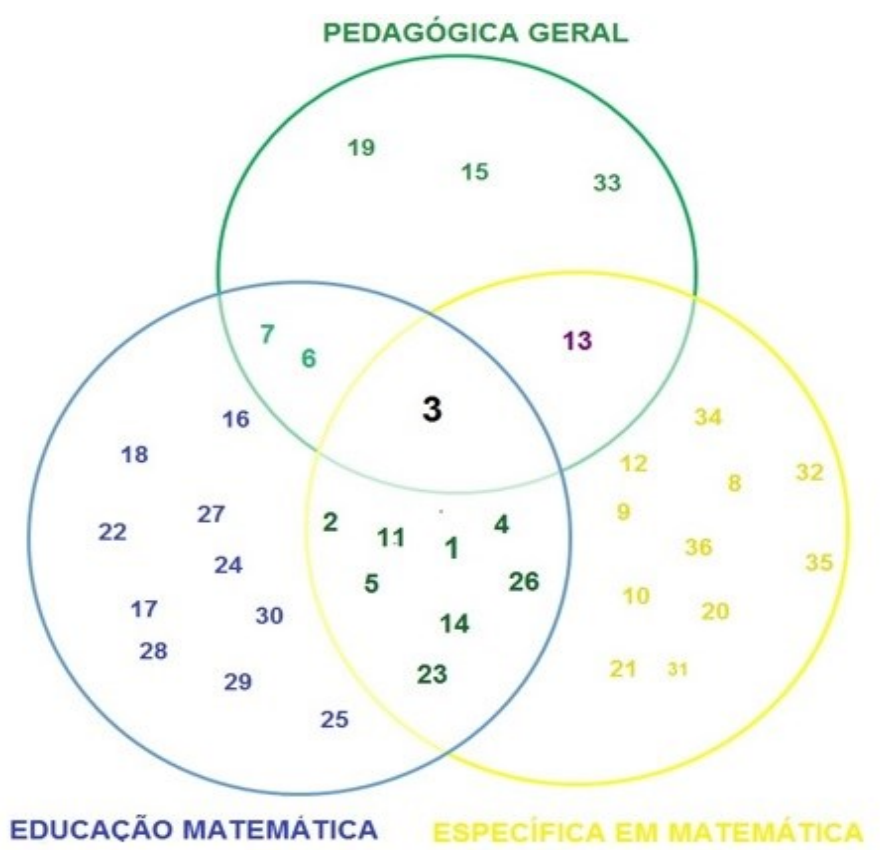

Fonte: Autoria própria (2017).

Da análise da figura observa-se que o item 3 - Apresentação/Seminário para a turma de um tema proposto - está situada na intersecção dos três conjuntos de atividades. Mas isso realmente tem seu foco na docência? A APCC tem o intuito de propiciar ao futuro professor aproximações com situações de docência. Nesse sentido, cabe-nos questionar de que modo a leitura de temas propostos e a apresentação em seminários realmente cumpre esse objetivo.

Continuando a análise do diagrama, a intersecção entre os eixos de Formação Específica e de Educação Matemática apresenta nove itens de semelhança, o que nos indica uma tentativa de diálogo entre as atividades desses dois eixos, possivelmente associada à natureza do conhecimento envolvido - a disciplina.

Com a intenção de ampliar o processo de análise dos dados documentais, para além do olhar sobre as APCCs listadas nos diferentes eixos formativos e suas recorrências em um ou outro eixo, interessou-nos analisar em especial os "tipos de práticas" indicadas e suas aproximações com o conceito de práxis, no movimento da atividade teórica e prática. Nessa direção, constituíram-se cinco grupos de análise, descritos a seguir.

O grupo 1 compreende as situações em que o acadêmico realiza atividades de APCC que envolvem documentos que o futuro professor deverá manusear e ter conhecimento, tais como a legislação, documentos oficiais e relatórios. Com isso, denominamos o primeiro grupo como "Atividades que envolvem análise, leitura ou elaboração de documentos oficiais, relatórios ou legislação educacional".

O grupo 2 é o conjunto de atividades em que o acadêmico tem contato com práticas do cotidiano da vida profissional de um professor. Questões que envolvem o conhecimento tanto teórico quanto prático da atividade docente, voltado à elaboração e planejamento de uma aula ou atividade, à confecção de materiais e elaboração e resolução de exercícios com a turma. São atividades subsidiadas tanto pelo elemento teórico quanto pelo elemento prático, que tem sua finalidade a prática do professor. Com isso denominamos o segundo grupo como "Atividades 
de criação, elaboração, planejamento de atividades ou materiais para a sala de aula".

O grupo 3 compreende as situações que envolvem leituras, apresentações, debates de textos, artigos, dissertações ou temas específicos para a disciplina, englobando temas de assunto da disciplina ou leituras complementares. Denominado então de "Atividades de leitura, debate, ou estudo de texto ou tema para disciplina". Atividades subsidiadas por elementos práticos e teóricos, mas que tem seu foco em itens teóricos que podem vir a subsidiar a atividade docente.

O grupo 4 envolve situações nas quais são solicitados na disciplina que se realize uma atividade específica para o momento, seja lista de exercícios, aplicação de exercícios ou resoluções. Nomeamos este grupo como "Atividades de fixação específicas para disciplina", pois não apresenta seu foco nem em atividades teóricas do futuro professor, nem em conhecimentos próprios da prática docente, e, ainda, não se desenvolve no sentido da práxis, mas sim de exercitação no sentido mais próximo de praticismo.

O último grupo é de atividades que não podemos classificar entre nenhuma das categorias anteriores, assim denominamos como "Outras atividades", em menor quantidade que as anteriores, tais como participação em evento da instituição, entrega de relatórios ou até mesmo a apresentação de um vídeo para a turma.

Em síntese, os grupos constituídos compuseram o seguinte quadro: 
Quadro 3 - Descrição dos grupos de APCCs por tipo de atividades

\begin{tabular}{|c|c|}
\hline Grupo & Itens pertencente ao grupo \\
\hline $\begin{array}{l}01 \text { - Atividades que envolvem análise, leitura } \\
\text { ou elaboração de documentos oficiais, } \\
\text { relatórios ou legislação educacional }\end{array}$ & $\begin{array}{l}12 \text { - Estudo de Legislação/Diretrizes. } \\
15 \text { - Análises de Projetos Políticos } \\
\text { Pedagógicos (PPP). } \\
19 \text { - Elaboração de projeto de pesquisa. } \\
23 \text { - Orientações para elaboração de } \\
\text { relatórios. } \\
29 \text { - Orientações para desenvolvimento de } \\
\text { projetos com Modelagem Matemática. } \\
35 \text { - Análise do livro didático. }\end{array}$ \\
\hline $\begin{array}{l}02 \text { - Atividades de criação, estratégias } \\
\text { didáticas, elaboração, planejamento de } \\
\text { atividades ou materiais para a sala de aula }\end{array}$ & $\begin{array}{l}05 \text { - Criação de Material concreto. } \\
06 \text { - Elaboração de atividade. } \\
07 \text { - Planejamento de uma aula. } \\
09 \text { - Elaboração de uma questão sobre o } \\
\text { tema proposto. } \\
11 \text { - Estudo de softwares no ensino de } \\
\text { Matemática. } \\
14 \text { - Uso de softwares no ensino de } \\
\text { Matemática. } \\
16 \text { - Análise de jogos para o ensino de } \\
\text { Matemática. } \\
18 \text { - Trabalho com material concreto. } \\
21 \text { - Apresentação para a turma de exercício } \\
\text { resolvido pelo aluno. } \\
24 \text { - Organização curricular e planejamento } \\
\text { didático. } \\
26 \text { - Aplicação do conteúdo proposto na } \\
\text { Educação Básica. } \\
27 \text { - Estudo de casos no ensino com } \\
\text { Modelagem Matemática. } \\
28 \text { - Estratégias didáticas que possibilitam o } \\
\text { uso de Modelagem Matemática em sala de } \\
\text { aula. } \\
34 \text { - Análise de conteúdo no livro didático. }\end{array}$ \\
\hline $\begin{array}{l}03 \text { - Atividades de leitura, debate, estudo de } \\
\text { texto ou tema para disciplina. }\end{array}$ & $\begin{array}{l}01 \text { - Leitura de artigo ou texto envolvendo } \\
\text { tema da disciplina } \\
03 \text { - Apresentação/Seminário para a turma de } \\
\text { um tema proposto. } \\
04 \text { - Pesquisa de artigo/Material para } \\
\text { disciplina. } \\
13 \text { - Discussão sobre tema proposto. } \\
17 \text { - Estudo de Tecnologias para deficientes } \\
\text { auditivos. } \\
22 \text { - Elaboração de um mapa conceitual. } \\
30 \text { - Discussão de Educação Ambiental e } \\
\text { Modelagem Matemática. } \\
33 \text { - Estudo dos textos de Paulo Freire. }\end{array}$ \\
\hline $\begin{array}{l}04 \text { - Atividades de fixação específicas para } \\
\text { disciplina }\end{array}$ & $\begin{array}{l}02 \text { - Resolução de exercicios propostos. } \\
10 \text { - Lista de exercícios. } \\
20 \text { - Aplicação de conteúdo proposto pela } \\
\text { disciolina. }\end{array}$ \\
\hline 05 - Outras atividades & $\begin{array}{l}08 \text { - Participação em evento da instituição. } \\
25 \text { - Entrega de relatório. } \\
31 \text { - Uso de Vídeo. } \\
32 \text { - Indicação do conteúdo matemático } \\
\text { trabalhado na aula. } \\
36 \text { - Descrição de APCC indefinida }\end{array}$ \\
\hline
\end{tabular}

Fonte: Autoria própria (2017).

Esse quadro nos permite observar as atividades propostas por meio de grupos de atividades, e não mais isoladamente. Com isso, nossa intenção é analisar as possíveis aproximações ao conceito de práxis, na articulação entre atividade teórica e atividade prática, buscando encontrar o conjunto de atividades de prática como componente curricular que estão almejando essa articulação.

Ao organizar os grupos, as atividades presentes no primeiro deles têm seu foco voltado para atividades teóricas, como estudo de legislação, análises de 
projetos políticos pedagógicos, elaborações de projetos e análises dos livros didáticos. Recorremos ao conceito de atividade teórica, entendendo que a “(...) atividade teórica não transforma a realidade embora sua existência esteja vinculada com a prática uma vez que fornece conhecimentos imprescindíveis para essa transformação." (MORETTI, 2007, p. 82).

O âmago dessas atividades encontra-se em propiciar ao futuro professor conhecimentos teóricos para sua atuação docente. Nesse conjunto de atividades, não encontramos, de modo geral, a possibilidade de articulação entre a teoria e a prática em uma formação para a práxis, pois elas lidam com documentos e estudos teóricos, e, assim como prática como componente curricular, elas acabam não oferecendo para o acadêmico essa experiência. Mesmo que as atividades sejam importantes para a docência, elas não estão diretamente corroborando no sentido da práxis pretendida. Cabe aqui destacar a necessidade de que essas propostas envolvam a relação com a educação escolar. Por exemplo: ao se estudar a legislação educacional, promover a aproximação com a escola procurando entender como esta se organiza frente às leis que a regem. Ao analisar um livro didático, investigar como este se articula à proposta pedagógica da escola, dentre outras possibilidades.

O maior leque de atividades encontra-se no grupo 2, que consideramos apresentar mais evidências de elementos teóricos e práticos na elaboração das atividades. Encontramos atividades de diversas características, dentre as quais destacamos o estudo e uso de softwares. Nessa atividade o acadêmico encontrase em dois movimentos: um primeiro de cunho teórico, em que é preciso por meio de estudos compreender os softwares que oportunizam melhores condições para o ensino da matemática, para posteriormente aplicar esses conhecimentos teóricos no uso dos softwares, com intuito de ensinar matemática. Assim, envolvendo uma formação em direção à práxis. Nesse sentido:

(...) a atividade do professor será entendida como práxis pedagógica, se se constituir na unidade entre a atividade prática e atividade teórica na transformação da realidade escolar. A práxis pedagógica ao ter como fundamento a prática docente, busca a teoria de modo que esta possa esclarecê-la e servir-lhe de guia ao mesmo tempo em que, num processo contínuo, permite o enriquecimento da teoria pela prática. (MORETTI, 2007, p. 94).

Esse movimento de correlação, no qual a teoria orienta as próximas ações que serão realizadas pelos acadêmicos, enriquece a formação do futuro professor, que encontra a possibilidade de planejar diferentes abordagens para o tratamento dos conhecimentos estudados. Por sua vez, durante ou posteriormente a aplicação, o acadêmico poderá refletir sobre a aplicação da atividade de prática como componente curricular e aperfeiçoar seu conhecimento teórico baseado em sua prática. Além disso, uma atividade que não se encontrava nas intersecções como a "Elaboração de uma questão sobre o tema proposto", pode oportunizar que o acadêmico relacione tanto os conhecimentos teóricos quanto práticos, pois é preciso revelar um movimento de apropriação dos conceitos matemáticos envolvidos nas questões, bem como pensar em quem irá resolvê-las, adequando a idade correta ao nível de dificuldade, dentre outros aspectos. Dessa forma: 
atividades mobilizadoras para a identificação, generalização e internalização ou apropriação de um modo generalizado de organização do ensino ou ainda, como assinala Rubtsov (1996), na aquisição de uma "forma de ação universal" (p. 131) (RIBEIRO, 2011, p. 63).

Além de elaborar uma questão, as descrições presentes na interseção do eixo de formação Pedagógica Geral e de Educação Matemática (Elaboração de uma atividade e Planejamento de uma aula) já analisadas - como APCCs de Organização Curricular, Análise de Jogos, estratégias no ensino de Modelagem Matemática também se encontram nesse grupo e vão ao encontro do exposto por Ribeiro (2011), oferecendo assim a oportunidade de o futuro professor desenvolver suas habilidades de ensino e aprendizagem.

Encontramos nesse grupo atividades que contribuem para que os acadêmicos utilizem conhecimentos teórico-práticos como possibilidades de organização da prática como componente curricular, pois elas não se limitam apenas ao momento da aplicação da atividade, ou seja, é necessário organizar as ações que irão ser realizadas. Assim, o acadêmico precisa encontrar formas de aplicar os conhecimentos adquiridos nas disciplinas específicas de conteúdo matemático, de educação matemática ou pedagógicas. Consideramos que esse grupo de atividades possibilitam ao acadêmico realizar atividades de aproximação e vivência de experiências ou de domínio de habilidades e conhecimentos próprios de ser professor, próprios da atuação docente, pois:

(...) a atividade teórica possibilita um conhecimento indispensável para transformar a realidade ou traça fins que antecipam idealmente sua transformação, subentende-se compreender a prática como fundamento e fim da teoria. No primeiro caso - a prática como fundamento da teoria implica entender a dinâmica por meio da qual a prática, mediante a produção material, contribui para ampliar o horizonte dos problemas e das soluções, determinando assim, o desenvolvimento e progresso do conhecimento. Por outro lado, no segundo caso - a prática como fim da teoria - consiste em entendê-la como antecipação ideal de uma prática ainda inexistente, ou seja, como teoria já elaborada que influi no desenvolvimento da prática. (RIBEIRO, 2011, p. 58).

Ao observar o conjunto de APCC do grupo analisado, percebemos o movimento que permite ao futuro professor experiências que utilizem a teoria para o enriquecimento de sua prática e de práticas que favoreçam o aperfeiçoamento de seus conhecimentos teóricos.

O destaque à proposição de atividades de elaboração e organização do ensino por parte dos futuros professores merece atenção nesse grupo, uma vez que propicia melhores condições de formação do professor na direção de sua autonomia para produzir suas aulas e seus materiais de ensino de modo autônomo e inovador.

No terceiro grupo de atividades, os acadêmicos realizaram atividades de cunho teórico. Nele, o foco é justamente o aperfeiçoamento de atividades teóricas, com estudo de textos e temas das disciplinas, e com isso:

(...) o conhecimento teórico é o conteúdo da atividade de estudo e, graças à apropriação desse tipo de conhecimento, desenvolvem-se neoformações 
escola, na perspectiva teórica adotada, deve organizar o ensino de maneira a promover o desenvolvimento dos estudantes. (ASBAHR, 2011, p. 69).

Embora muitas das atividades realizadas nesses grupos de afinidades possam se relacionar com o grupo 2, por utilizarem um mecanismo imprescindível para o futuro professor - o estudo teórico - que poderá modificar a sua prática e desenvolver a sua formação do pensamento teórico, por meio dessas atividades de estudo, é importante atentar para alguns tipos de APCC que possam ser confundidas somente como atividades de leitura, pois a atividade teórica não pode se sobrepor ao contexto prático, uma vez que "A atividade teórica proporciona um conhecimento indispensável para transformar a realidade, ou traça fins que antecipem idealmente sua transformação, mas tanto em um como no outro caso a realidade efetiva permanece intacta." (SÁNCHEZ VÁZQUEZ, 2011, p. 234).

O conhecimento teórico tem que oportunizar aos acadêmicos essa antecipação para que eles possam estar preparados quando forem atuar na docência. No caso da APCC também é imprescindível oferecer aos acadêmicos a experiência da docência, pois assim, esse grupo de atividade, focalizado na atividade teórica, acaba por não se aproximar do que se espera da APCC, na essência do conceito abordado no decorrer do trabalho.

Não se trata aqui de menosprezar a importância de atividades de estudo e debates de texto, mas sim de evidenciar a importância de que essas propostas sejam ancoradas em situações voltadas à vivência da realidade educativa. Por exemplo, ao realizar o estudo teórico de um texto sobre avaliação educacional e instrumentos avaliativos, propor situações em que os licenciandos tenham que analisar instrumentos de avaliação utilizados comumente em aulas de matemática, procurando compreender neles as concepções e intencionalidades presentes.

\section{CONSIDERAÇÕES FINAIS}

Finalizamos o presente artigo retomando o entendimento de que a práxis é uma atividade transformadora da realidade e adequada a um fim, mas essa atividade não é puramente material; ela produz, além dos fins, o conhecimento que caracteriza a atividade teórica (SÁNCHEZ VÁZQUEZ, 2011). Dessa compreensão, destacamos o entendimento da prática como componente curricular trilhando o caminho da atividade teórica e da atividade prática ao situar que "Por meio destas atividades, são colocados em uso, no âmbito do ensino, os conhecimentos, as competências e as habilidades adquiridas nas diversas atividades formativas que compõem o currículo do curso." (BRASIL, 2015, p. 3).

Como bem contempla a definição de práxis apresentada por Sanchez Vázquez (2011), ao abordar a transformação da realidade ofertada pela atividade prática nas atividades elaboradas de APCC, ao pôr em uso, no ambiente de ensino, os conhecimentos teóricos que sustentam a atividade da docência, caracterizados pela atividade teórica, é que se manifestam as condições de articulação teoria e prática.

Neste contexto, para a organização da atividade de prática como componente curricular, ressaltamos a necessidade de um sistema de dependência mútua como sugerido na figura: 
Figura 3 - Articulação teoria e prática na APCC

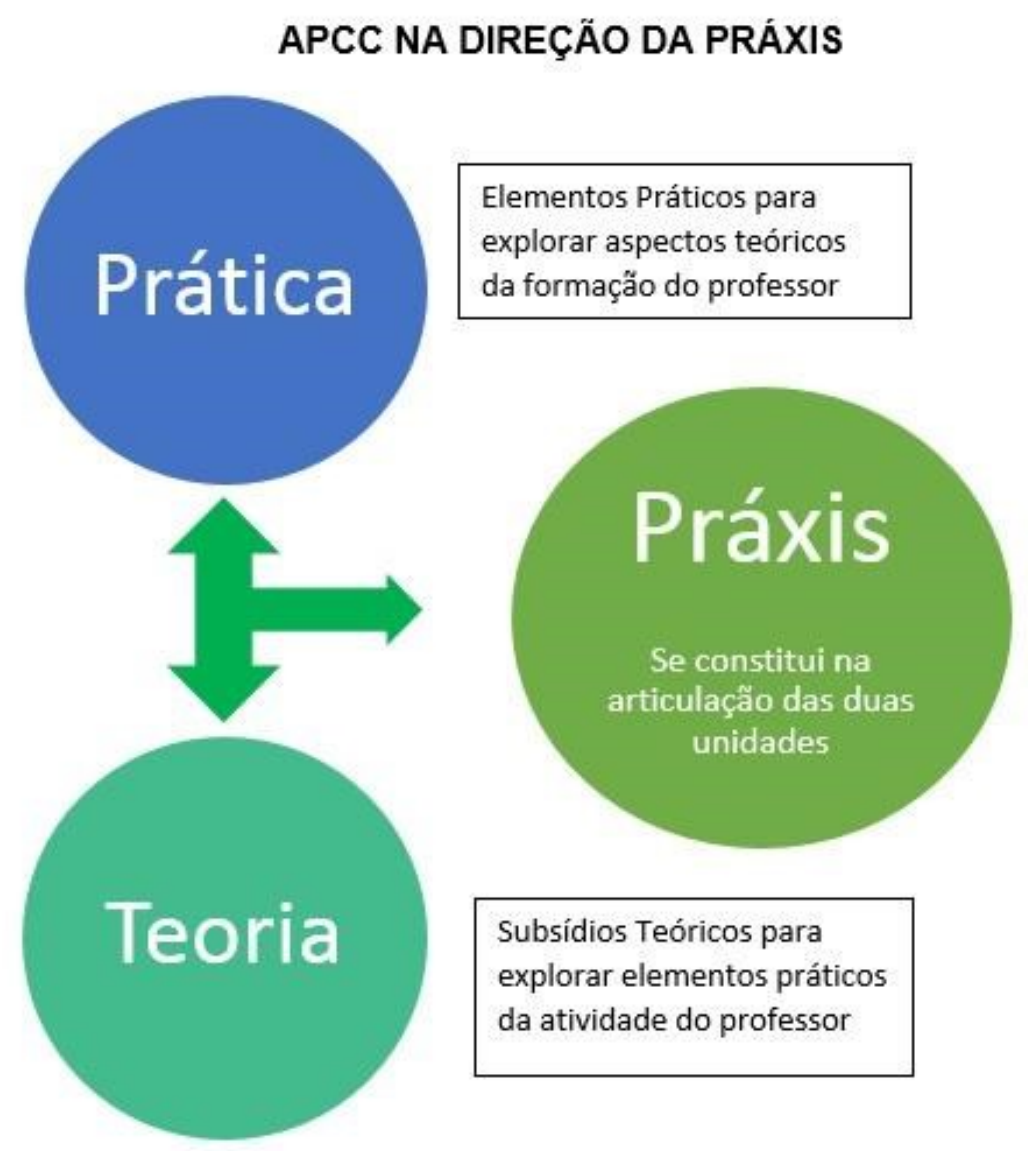

Fonte: Autoria própria (2017).

Ao encontrar uma convergência entre as atividades analisadas individualmente e o grupo de atividades que indicam práticas como componente curricular voltadas para a criação, elaboração, planejamento, e aplicação de conteúdo na educação básica (subsidiados por estudos teóricos do tema e conhecimentos práticos), evidenciamos indícios de aproximação do conceito de APCC na direção da práxis, como explicitado no referencial adotado.

Outro aspecto a se destacar é o fato dessas atividades estarem ocorrendo tanto em disciplinas específicas em conteúdos matemáticos, como em atividades desenvolvidas por professores que lecionam nos eixos de Educação Matemática e Pedagógica Geral, o que revela um movimento de compreensão mais orgânico no curso como um todo.

Assim, ao colocar luz sobre as atividades desenvolvidas como APCCs, buscouse trazer contribuições aos professores formadores na organização de suas atividades de ensino. Foram elencadas características reveladoras que dão indícios de articulação entre teoria e prática para a proposição de práticas como componente curricular. Características que para além dos requisitos mínimos, comtemplem a essência do conceito de práxis, como articulação da atividade teórica e da atividade prática. 


\title{
Practice as a curricular component in an undergraduate course in mathematics: an analysis from the perspective of activity theory
}

\begin{abstract}
The article is based on a master's degree research and had the objective of investigating possibilities for the organization of practice as curricular component (APCC) that could favor the articulation between theory and practice in the initial formation. The study was realized in a Teaching Degree in Mathematics, based on the theoretical assumptions of activity theory, among which stand out the concepts of theoretical activity, practical activity and praxis. For the development of the research, the documentary research was adopted, using the class diaries and the detailed teaching plans of the subjects taught in the first semester of 2015 and that presented part of their workload destined to practice as curricular component of the course in study. As a theoretical reference, the study was based in Leontiev $(1983,1988)$ for the discussion of elements of activity theory and in Sánchez Vázquez $(1980,2011)$ for the deepening of the concepts of theoretical activity, practical activity and praxis. The analysis process took place under two aspects: i) the presence of the APCCs in the three training axes foreseen in the course and; ii) the nature of the APCC activities present in the course. In this first aspect the analysis focused on understanding the recurrences of activities understood as APCCS in the axes of specific training of mathematical content, general pedagogical training and training in mathematical education. In the second aspect of analysis five groups of activities were constituted, among which the group "Creation activities, didactic strategies, elaboration, planning of activities or materials for the classroom" revealed more clues of possible links between theory and practice. The research sought to discuss the activities developed as APCCs, to bring contributions to the teacher trainers in the organization of their teaching activities, choosing characteristics of activities that reveal evidence of link between theory and practice.
\end{abstract}

KEYWORDS: Practice as curricular component. Theoretical activity. Practical activity. Praxis. Degree in mathematics. 


\section{AGRADECIMENTOS}

À Coordenação de Aperfeiçoamento de Pessoal de Nível Superior (CAPES) por possibilitar as condições de realização dessa pesquisa.

\section{REFERÊNCIAS}

A ASBAHR, F. da S. F. "Por que aprender isso, professora?": Sentido pessoal e atividade de estudo na Psicologia Histórico-Cultural. 2011. 220 f. Tese (Doutorado) - Curso de Programa de Pós-graduação em Psicologia, Instituto de Psicologia da Universidade de São Paulo, Universidade de São Paulo, São Paulo, 2011.

BRASIL. Parecer n.o CNE/CP 28/2001, de 02 de outubro de 2001. Ministério da Educação. Conselho Nacional De Educação. Dá nova redação ao Parecer CNE/CP 21/2001, que estabelece a duração e a carga horária dos cursos de Formação de Professores da Educação Básica, em nível superior, curso de licenciatura, de graduação plena.

BRASIL. Resolução CNE/CP 1, de 18 de fevereiro de 2002. Ministério da Educação. Conselho Nacional de Educação. Diretrizes Curriculares Nacionais para a Formação de Professores da Educação Básica, em nível superior, curso de licenciatura, de graduação plena, 2002a.

BRASIL. Resolução CNE/CP 2, de 19 de fevereiro de 2002. Ministério da Educação. Conselho Nacional de Educação. Diretrizes Curriculares Nacionais para a Formação de Professores da Educação Básica, em nível superior, curso de licenciatura, de graduação plena, 2002b.

BRASIL. Resolução CNE/CP 2, de 1ㅇ de julho de 2015. Ministério da Educação. Conselho Nacional de Educação. Define as Diretrizes Curriculares Nacionais para a formação inicial em nível superior (cursos de licenciatura, cursos de formação pedagógica para graduados e cursos de segunda licenciatura) e para a formação continuada, 2015.

DANIELS, H. Abordagens atuais da teoria sociocultural e da teoria da atividade. In: DANIELS, H. Vygotsky \& a Pedagogia. São Paulo: Loyola, 2003.

LEONTIEV, A. Actividad, conciencia, personalidad. Cuba: Editorial Pueblo y educación, 1983.

MORETTI, V. D. Professores de Matemática em Atividade de Ensino: uma 
MORETTI, V. D. e MOURA, M. O. de. Professores de Matemática em Atividade de Ensino: Contribuições da Perspectiva Histórico-Cultural para Formação Docente. Ciência \& Educação, v. 17, n. 2, p. 435-450, 2011.

RIBEIRO, F. D. A aprendizagem da docência na prática de ensino e no estágio: contribuições da teoria da atividade. 2011. 196 f. Tese (Doutorado) - Curso de Programa de Pós-graduação em Educação, Universidade de São Paulo, São Paulo, 2011.

SÁNCHEZ VÁZQUEZ, A. Filosofia da Práxis: Unidade da Teoria e da Prática. In: MAGALHÃES-VILHENA, V. de (Org.). Práxis: Categoria Materialista de Prática Social (Vol II). Lisboa: Livros Horizonte, 1980. p. 9-38.

SÁNCHEZ VÁZQUEZ, A. Filosofia da práxis. 2. ed. São Paulo: Expressão Popular, 2011.

SOUZA, F. D. de; MORETTI, V. D. Sobre a prática na formação de professores de Matemática no Brasil: das diretrizes legais à essência do conceito. In: KALINKE, M. A.; MOCROSKY, L. F. (Org.). Educação matemática: pesquisas e possibilidades. Curitiba: UTFPR, 2015. p. 27-46.

UTFPR. Projeto de abertura do curso de licenciatura em matemática. Curitiba, agosto de 2010. Disponível em http://www.utfpr.edu.br/curitiba/estruturauniversitaria/diretorias/dirgrad/departamentos/matematica/licenciatura/arquivo /projeto_criacao_matematica.pdf. Acesso em 30/05/2015.

Recebido: 02 jan2017

Aprovado: 20 abr. 2018

DOI: $10.3895 /$ actio.v3n2.7580

Como citar:

BORINI, R. B. M. C.; SOUZA, F. C. Prática como componente curricular em um curso de licenciatura em matemática: uma análise à luz da teoria da atividade. ACTIO, Curitiba, v. 3, n. 2, p. 39-57, mai./ago. 2018. Disponível em: <https://periodicos.utfpr.edu.br/actio>. Acesso em: XXX

Correspondência:

Rafael Borini Martins Costa Borini

Rua Carolina Vailatti, n. 75, Bairro São Judas, Itajaí, Santa Catarina, Brasil.

Direito autoral: Este artigo está licenciado sob os termos da Licença Creative Commons-Atribuição 4.0

Internacional.

(c) (i) 